\title{
Characterizing woodland caribou habitat in sub-boreal and boreal forests
}

\author{
Chris J. Johnson ${ }^{1}$, Nancy D. Alexander, Roger D. Wheate*, \\ Katherine L. Parker \\ Faculty of Natural Resources and Environmental Studies, University of Northern British Columbia, \\ 3333 University Way, Prince George, BC, Canada V2N 4Z9
}

Received 3 June 2002; accepted 20 November 2002

\begin{abstract}
Woodland caribou (Rangifer tarandus caribou) are sensitive to changes in understory vegetation resulting from forest harvesting and are, therefore, of special concern for foresters and habitat biologists. Effective management of this species requires reliable habitat inventories which, because of the large heterogeneous areas over which caribou range, can be costly. We used Landsat Thematic Mapper (TM) imagery and digital elevation data to identify 23 vegetative cover types across the $5100 \mathrm{~km}^{2}$ range of the Wolverine caribou herd of northcentral British Columbia, Canada. The classification was augmented with available geographical information system (GIS) data for a total of 27 cover types. We achieved an overall accuracy of $76.7 \%$ based on known ground samples; however, accuracy varied according to cover type. Considering the size of the study area, the procedure we employed was relatively cost effective and efficient. We discuss the advantages of such an approach for wildlifehabitat studies reliant on large-scale vegetation maps.
\end{abstract}

(C) 2002 Elsevier Science B.V. All rights reserved.

Keywords: Caribou; Landsat TM; Lichen; Supervised classification

\section{Introduction}

Across North America, woodland caribou (Rangifer tarandus caribou) have become a high priority species for management (Cumming, 1992). Historical trends of declining populations or extirpated herds have necessitated management schemes that will not only conserve and stabilize existing populations, but possibly enhance others (Edmonds, 1988). In British

\footnotetext{
* Corresponding author. Tel.: +1-250-960-5865. E-mail address: wheate@unbc.ca (R.D. Wheate).

${ }^{1}$ Present address: Department of Biological Sciences, University of Alberta, Edmonton, Alta., Canada T6G 2E9.
}

Columbia (BC), Canada, a demand for merchantable timber has led to a heightened awareness of the conflict between human encroachment and the habitat requirements of caribou. To meet the needs of both caribou and industry, information on the habitat requirements and population dynamics of caribou is essential.

Identification of vegetation communities that may constitute habitat is a necessary requirement of most research projects or management schemes designed to understand or conserve large-ranging species. In BC, forest inventory data has traditionally served as the basis for examining caribou-habitat relationships (e.g. Apps et al., 2001) and for implementing small-scale operational and large-scale planning objectives for 
caribou. Those data are spatially represented at a scale of 1:20,000; features typically related to caribou ecology include canopy species and closure, site productivity, stand age, and stocking density. In some areas of the province, however, the inventory is out of date or is of inconsistent quality for analyses and management efforts conducted at the scale of individual patches. Biologists are also forced to use forest stand characteristics to generate ecological associations with assumed relevance to caribou. Furthermore, areas that are unproductive for forest species are typically not mapped (e.g. alpine habitats). As a replacement, terrestrial ecosystem mapping (TEM) was conceived to capture the ecological associations of vegetation, soils, local and regional climatic conditions, and the resulting relationships with wildlife habitat (Resources Inventory Committee, 1998). High costs and lengthy completion times have hindered the implementation of TEM across the province.

Classification of Landsat Thematic Mapper (TM) imagery in conjunction with readily available ancillary information such as digital terrain data may provide a relatively low-cost alternative for mapping vegetative communities that serve as wildlife habitat. The technique has been applied to species such as muskox (Ovibos moschatus), bison (Bison bison), whitetail deer (Odocoileus virginianus) and waterfowl, and can be especially cost effective when considering the large areas over which species such as woodland caribou range (Ormsby and Lunetta, 1987; Ferguson, 1991; Matthews, 1991; Morrison, 1997). We assessed the utility of Landsat TM imagery and ancillary geographical information system (GIS) data to accurately identify vegetation communities with ecological meaning to caribou-habitat relationships in northcentral BC. Our results have application to other boreal and sub-boreal systems and demonstrate the relative ease and reliability of using remote sensing to identify vegetation communities for conservation research and management across large study areas.

\section{Materials and method}

\subsection{Study area}

The $5100 \mathrm{~km}^{2}$ area chosen for study was that used by the Wolverine herd (Heard and Vagt, 1998), located approximately $250 \mathrm{~km}$ northwest of Prince George, BC (Fig. 1). The terrain varies, from valley bottoms at approximately $900 \mathrm{~m}$ to alpine summits at $2050 \mathrm{~m}$, and is characterized by numerous vegetation associations resulting from diverse topography, soils, and succession. Forest types below $1100 \mathrm{~m}$ have been influenced extensively by wildfires and are dominated by lodgepole pine (Pinus contorta), white spruce (Picea glauca), hybrid white spruce (P.glauca $\times$ Picea engelmannii), and subalpine fir (Abies lasiocarpa). Between 1100 and $1600 \mathrm{~m}$, a moist cold climate prevails with forest types consisting primarily of Engelmann spruce ( $P$. engelmannii) and subalpine fir. Elevations above $1600 \mathrm{~m}$ are alpine tundra and are distinguished by gentle to steep windswept slopes vegetated by shrubs, herbs, bryophytes, and lichens with occasional trees in krummholz form (Meidinger and Pojar, 1991).

\subsection{Data acquisition and classification}

In 1997, we conducted a review of available vegetation and ecological mapping suitable for assessing the movements and habitat relationships of the Wolverine caribou herd. Existing sources were found to be inaccurate or were of insufficient area to meet project objectives (C. Johnson, unpublished data). Relative to conventional approaches dependent on aerial photographs and extensive field investigations, the most cost-effective option was to use Landsat TM imagery to classify the vegetation communities and other cover types found across the caribou range.

We developed an initial stratification of cover types with potentially unique spectral qualities using the legend and associated ecological data from a previous mapping project (McKenzie, 1993) that covered a portion of the study area. A fixed-wing aircraft was used to assess the study area and collect oblique photographs of vegetation associations. From 9 June to 15 July 1998 , we visited and recorded the location and characteristics of suitable patches of vegetation to serve as training sites for the classification procedure. Sampling frequency for each predefined cover type was dependent on heterogeneity of vegetation (i.e. spectral reflectance).

A seven band Landsat TM dataset was acquired for 22 August 1992 (track 50/frame 21). This date was selected to optimize the photosynthetic potential of the 


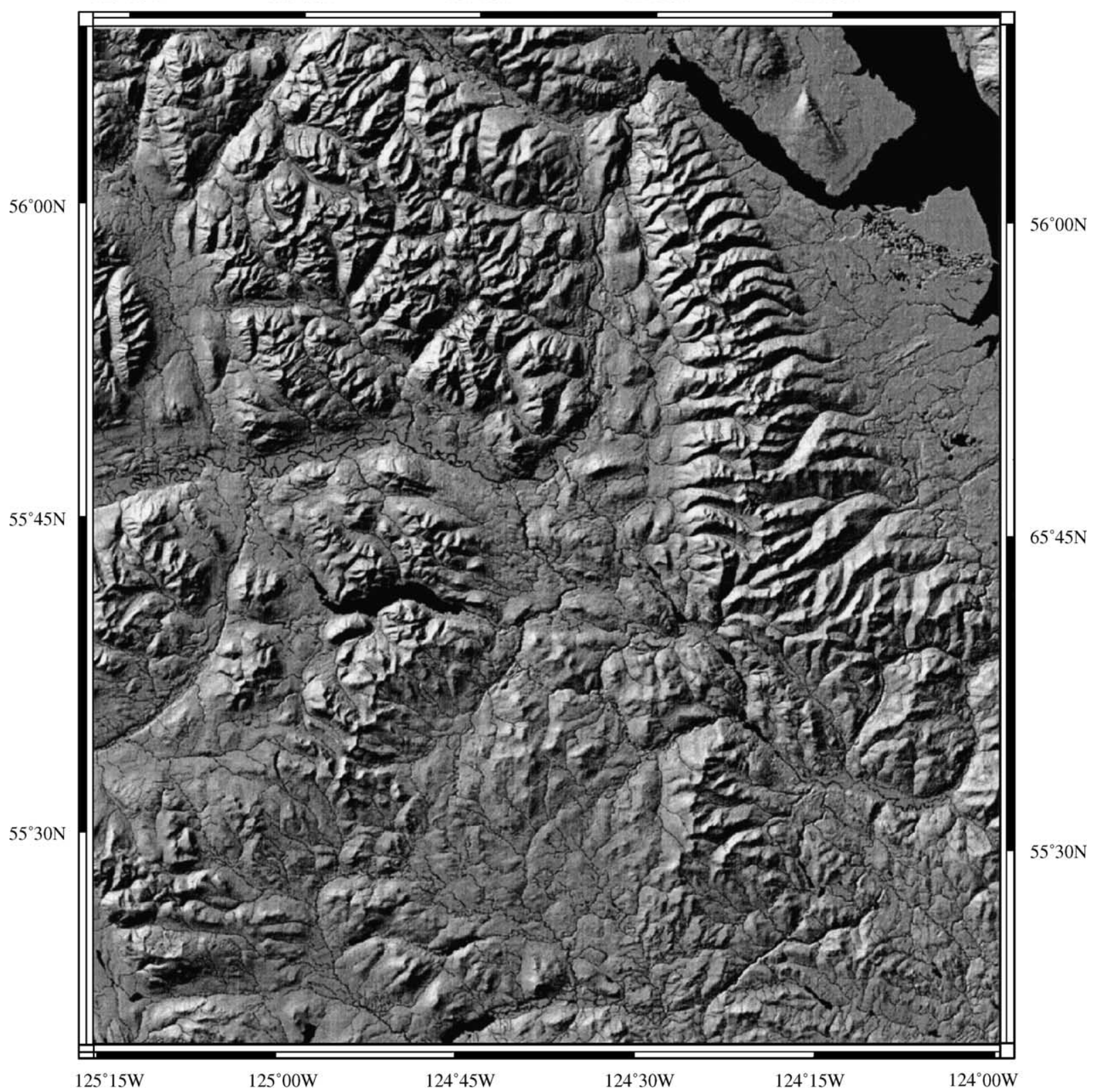

Fig. 1. The Wolverine caribou study area in northcentral BC, Canada (shaded relief model from BC TRIM digital data).

vegetation while minimizing snow cover at high elevations. Forest companies with cutting rights in the study area provided digital files of clearcut boundaries. A digital elevation model generated from 1:20,000 provincial Terrain Resource Inventory Management
(TRIM; British Columbia Ministry of Crown Lands, 1990) data was used to produce layers of slope and incidence. Roads, trails, lakes, and rivers were also extracted from the TRIM data. The study area was clipped from the full Landsat scene and georectified 
using 57 ground control points of road intersections and river junctions selected from the TRIM thematic data (RMS error $=0.88$ pixel; Kardoulas et al., 1996).

We used a supervised maximum-likelihood procedure (Lillesand and Kiefer, 1994) and a dataset consisting of Landsat bands TM 3 (Red), TM 4 (near infrared), TM 5 (mid-infrared), elevation, slope, incidence, and a normalized difference vegetation index (NDVI) to classify the image. The NDVI channel is a composite of TM 4 and TM 3 and gives an estimate of green biomass. Two hundred and seventy-eight training sites defined the spectral qualities of the identified cover types. Training classes derived from these sites were analyzed and merged where there was poor discrimination. Following classification, we used a modal filter to remove single isolated pixels and aggregate small patches below a minimum of 4 ha.

A second set of independent ground-truth points was used to assess the accuracy of the classification. Because of the large study area and lack of road access we did not adopt a stratified or truly random strategy for sampling truth points. Instead, 473 independent assessment locations were taken from the original field data of the McKenzie project (1993), vegetation data gathered during investigations of caribou foraging sites (Johnson et al., 2001), visits to sites accessible by road, and identifiable homogenous patches identified on monochrome air photos and oblique color slides. We believe that our truth points were representative of the cover types found across the study area and that variation in data sources controlled for systematic biases in sampling. We identified ground-truth sites as one of the classification cover types and based on correspondence with our classified imaged calculated several measures of accuracy (Congalton et al., 1983). Overall accuracy represents the percentage of truth sites that correspond with the classified image. Producer's accuracy is a measure of classified pixel omission from the correct cover type while user's accuracy is a measure of commission or false inclusion of pixels within the specified cover type. The kappa $(\kappa)$ statistic represents the improvement in the observed classification over one based on chance.

Landscape features of a small area (approximately two to three pixels), such as roads or minor waterways, can be difficult to capture with Landsat satellite imagery and may be lost during post-classification smoothing. To represent those features, we extracted roads, trails, lakes, and rivers from the TRIM data and integrated them with the final map. Since the imagery was approximately 6 years old, clearcut boundaries recorded as of 1996 were applied to the final image. Classification and image manipulation procedures were performed with Easi/Pace software (PCI Geomatics, Richmond, Ont., Canada).

\section{Results and discussion}

Using a supervised classification we identified 23 cover types (Table 1). Four additional types were created following the merging of the supervised classification and the TRIM lakes, roads/trails, rivers, and clearcut boundary GIS coverages. We achieved an overall classification accuracy of $76.7 \%$ and a $\kappa$ statistic of 0.748 (Table 2). The $\kappa$ statistic indicates that the observed classification was nearly $75 \%$ better than chance. Our results were similar to other classifications of boreal forests across variable terrain. For example, Franklin and Moulton (1990) achieved an accuracy of $77.6 \%$ when conducting a supervised classification using a Landsat image in conjunction with a digital elevation model of a $250 \mathrm{~km}^{2}$ area of southwest Yukon, Canada. Our accuracy values were, however, variable across cover types. Pine-lichen had a user's accuracy of $98.6 \%$, whereas the spruce cover type had an accuracy of only $50 \%$ (Table 2). For that cover type, black spruce, Abies-spruce, spruce-pine, and pine-black spruce were mistakenly classified as spruce (i.e. errors of commission; Table 2). Development and interpretation of the accuracy assessment was limited by small sample sizes of ground-truth sites for some cover types. We could not confidently identify any assessment sites for the Abies type and had small sample sizes for other cover types including alpine-shrub, alpine-moist/shrub, and rockfall. Measures of accuracy for cover types with few groundtruth sites are less reliable and likely highly variable depending on the sample used for assessment.

Typically, underrepresented cover types were difficult to identify with air photos or color slides and were inaccessible by road. Recommendations on sample size vary, but Congalton (1991) suggested that the minimum number of samples per cover type should 
Table 1

Cover types produced from a supervised classification of a Landsat TM image of the Wolverine caribou study area

\begin{tabular}{|c|c|c|}
\hline Cover type & Area (ha) & Description $^{\mathrm{a}}$ \\
\hline Aspen & 37,163 & Shrub or closed stands of Populus tremuloides that may be associated with $P$. contorta \\
\hline Pine & 49,804 & $\begin{array}{l}\text { Dominated by } P \text {. contorta, but may occur with a component of } P \text {. mariana or } P \text {. engelmannii } \times P \text {. } \\
\text { glauca in older stands; understory is characterized by feather mosses }\end{array}$ \\
\hline Spruce & 46,357 & $\begin{array}{l}\text { Dominated by } P \text {. engelmannii } \times P \text {. glauca, but may be a minor component of } P \text {. mariana or } P \text {. } \\
\text { contorta }\end{array}$ \\
\hline Lake & 28,345 & Permanent water bodies \\
\hline Avalanche track & 1,993 & $\begin{array}{l}\text { Active avalanche chutes and associated colluvial fans; shrub-dominated with } \\
\text { herbaceous openings }\end{array}$ \\
\hline Alpine-little vegetation & 9,574 & Wind-swept alpine ridge-tops or upper slopes with little vegetative cover \\
\hline Alpine-shrub & 13,780 & Moderate to steep alpine slopes with extensive cover of Betula glandulosa \\
\hline Black spruce & 14,248 & Water table at or near the surface consisting of open stunted forests of $P$. mariana \\
\hline Sedge bog & 21,834 & Shrub/sedge and forb dominated wetlands on depression landscapes with high water tables \\
\hline Shrub bog & 12,893 & Drier variant of sedge bog with $\sim 50 \%$ cover of $B$. glandulosa or Salix spp. and stunted P. mariana \\
\hline Alpine-moist shrub & 289 & Moist meadows typically in alpine bowls or cirques \\
\hline Rockfall & 9,036 & Steep rocky terrain with sparse vegetation and lichen-dominated cover \\
\hline Krummholz & 45,062 & Shrub cover of subalpine fir on gentle to moderate slopes (parkland) \\
\hline Alpine-grass shrub & 1,935 & $\begin{array}{l}\text { Alpine areas with deep soil on gentle to moderate slopes; grass-dominated cover; Stereocaulon, } \\
\text { Cetraria, and Cladina spp. found in less productive openings }\end{array}$ \\
\hline Abies-spruce & 99,841 & Mid-elevation stands on moderate to steep slopes dominated by A. lasiocarpa and $P$. engelmannii \\
\hline Spruce-pine & 29,371 & $\begin{array}{l}\text { Stands at lower elevations consisting of } P \text {. engelmannii } \times P \text {. glauca and } P \text {. contorta; poorly to } \\
\text { moderately developed shrub and herb layers }\end{array}$ \\
\hline Bedrock/no vegetative cover & 12,984 & $\begin{array}{l}\text { Rocky terrain with sparse vegetation restricted to pockets of soil; lichen-dominated cover of } \\
\text { Umbilicaria, Cetraria, and Cladina spp. }\end{array}$ \\
\hline Pine-black spruce & 49,224 & $\begin{array}{l}\text { Older } P \text {. contorta-P. mariana stands found on level to moderate slopes; associated with patches of } \\
\text { Cladina and Cladonia spp., but characteristically feather mosses }\end{array}$ \\
\hline Cottonwood & 1,279 & Active floodplains dominated by $P$. balsamifera, and Salix spp. \\
\hline Abies & 7,252 & Mid-elevation stands on moderate to steep slopes dominated by A. lasiocarpa \\
\hline Abies-pine & 21,257 & $\begin{array}{l}\text { Dry shedding ridge tops and mid-elevation stands found on moderate to steep slopes composed of } \\
\text { open stands of A. lasiocarpa and P. contorta; Cladina and Cladonia spp. found on dryer sites }\end{array}$ \\
\hline Pine-lichen & 19,949 & $\begin{array}{l}\text { Level glaciofluvial terraces and other features with well-drained soils that support stands of } P \text {. } \\
\text { contorta and an understory of Cladina and Cladonia spp. }\end{array}$ \\
\hline Abies-spruce-pine & 110,238 & $\begin{array}{l}\text { Mid-elevation stands of } A \text {. lasiocarpa, } P \text {. engelmannii, and } P \text {. contorta found on moderate to } \\
\text { steep slopes }\end{array}$ \\
\hline Clearcut & 51,965 & Areas recently harvested ( $<20$ years) and at an early stage of successional development \\
\hline River & 19,082 & Moving watercourses \\
\hline Road/trail & 5,220 & Roads and trails primarily used for motor vehicle access \\
\hline Anthropogenic & 25 & Agricultural lands or areas disturbed by placer mining \\
\hline
\end{tabular}

${ }^{\text {a }}$ For a more complete description of cover types, see Johnson (2000).

range from 75 to 100 . In our study, this would have required up to 2300 independent, identifiable, and homogenous locations. By that standard, our accuracy assessment was considered preliminary and forced us to adopt a conservative interpretation of the final classified image.

We did not perform an accuracy assessment of the TRIM lakes, roads/trails, and rivers, but relative to the Landsat-derived cover types are confident in their associated planimetric accuracy. Terrain Resource Inventory Mapping is conducted at a scale $(1: 20,000)$ larger than the resolution of Landsat imagery $(\sim 1: 50,000)$ and $90 \%$ of all well-defined planimetric features are within $10 \mathrm{~m}$ of their true position (British Columbia Ministry of Crown Lands, 1990). We are uncertain of the practices or accuracy standards used to survey and digitize the clearcut boundaries. In several locations, we observed boundaries that extended one to two pixels beyond the edge of clearcuts found on the classified image. This error of commission was likely less than would result from classifying clearcuts using a spectral signature that coincided with other deciduous 
Table 2

Classification accuracy for individual cover types resulting from a supervised classification of the Wolverine caribou study area ${ }^{a}$

\begin{tabular}{|c|c|c|c|c|}
\hline Cover type ${ }^{\mathrm{b}}$ & $\begin{array}{l}\text { Producer's } \\
\text { accuracy } \\
(\%)\end{array}$ & $\begin{array}{l}\text { User's } \\
\text { accuracy } \\
(\%)\end{array}$ & $\kappa$ & $\begin{array}{l}\text { No. of } \\
\text { sites }\end{array}$ \\
\hline Aspen & 93.9 & 75.6 & 0.738 & 33 \\
\hline Pine & 82.4 & 93.3 & 0.925 & 51 \\
\hline Spruce & 68.8 & 50.0 & 0.483 & 16 \\
\hline Avalanche track & 71.2 & 97.4 & 0.970 & 52 \\
\hline Alpine-little vegetation & 84.6 & 91.7 & 0.909 & 39 \\
\hline Alpine-shrub & 50.0 & 50.0 & 0.494 & 6 \\
\hline Black spruce & 52.4 & 61.1 & 0.593 & 21 \\
\hline Sedge bog & 76.5 & 100 & 1.000 & 17 \\
\hline Shrub bog & 93.3 & 90.3 & 0.897 & 30 \\
\hline Alpine-moist shrub & 100 & 100 & 1.000 & 1 \\
\hline Rockfall & 100 & 77.8 & 0.774 & 7 \\
\hline Krummholz & 87.5 & 71.8 & 0.698 & 32 \\
\hline Alpine-grass shrub & 75.0 & 85.7 & 0.855 & 8 \\
\hline Abies-spruce & 28.6 & 40.0 & 0.391 & 7 \\
\hline Spruce-pine & 62.5 & 76.9 & 0.761 & 16 \\
\hline $\begin{array}{l}\text { Bedrock/no vegetative } \\
\text { cover }\end{array}$ & 66.7 & 33.3 & 0.329 & 3 \\
\hline Pine-black spruce & 65.0 & 38.4 & 0.355 & 20 \\
\hline Cottonwood & 77.8 & 87.5 & 0.873 & 9 \\
\hline Abies & $\mathrm{NA}^{\mathrm{c}}$ & NA & NA & NA \\
\hline Abies-pine & 100 & 33.3 & 0.332 & 1 \\
\hline Pine-lichen & 87.7 & 98.6 & 0.983 & 81 \\
\hline Abies-spruce-pine & 68.8 & 78.6 & 0.778 & 16 \\
\hline Anthropogenic & 100 & 100 & 1.000 & 7 \\
\hline
\end{tabular}

${ }^{\text {a }}$ Overall accuracy was $76.7 \%$ with a $\kappa$ statistic of 0.748 .

${ }^{\mathrm{b}}$ See Table 1 for description of cover types.

${ }^{\mathrm{c}}$ Insufficient number of ground-truth sites to calculate accuracy assessment.

cover types. Augmenting the classified image with ancillary GIS data enhanced the interpretability and usefulness of the final map.

To reduce uncertainty, we grouped those cover types with poor accuracy statistics (Table 2) or with few assessment locations. Combinations were based upon errors of commission (i.e. cover types that were inclusive within another class), our knowledge of caribou-habitat relations (Johnson, 2000), and the observed ecological similarities between the 27 identified cover types. Where possible, we attempted to maintain the singularity of those cover types with known relevance to caribou biology (e.g. pine-lichen).

Our composite image consisted of 17 cover types which, for purposes of multivariate resource selection analyses, we later compressed to 12 types. That number of ecological associations was considerably less than the 72 vegetative classes of various serial stages that McKenzie (1993) documented using air photos at a scale of 1:70,000. Many of those classes, however, would need to be amalgamated before performing a statistically tractable analysis of habitat selection. We improved upon ecological maps that could be constructed with forest inventory data. For example, our final classification discriminated three alpine, two wetland, and krummholz cover types, none of which are considered during forest inventories. Subsequent analyses revealed that, depending on the scale of movement, caribou differentially selected among alpine cover types (Johnson et al., 2002). Creating a composite image of the original 27 cover types sacrificed some detail likely with relevance to understanding the movements and ecology of caribou. Of note, poor accuracy values forced us to combine black spruce with the larger pine-black spruce class; previous studies suggested selection by caribou for the black spruce cover type (Terry and Wood, 1999).

Caribou feeding sites and animal relocations collected with global positioning system (GPS) collars corresponded with several cover types. Fig. 2 illustrates differences in percent occurrence of cover types for small-scale movements of caribou and corresponding random sites. As reported for our site investigations and multivariable resource selection analyses, the difference between used and random sites infers selection by caribou for pine-lichen and alpine-rock (Johnson et al., 2001, 2002). The accuracy assessment suggests that pine-lichen has a spectral signature distinctive from the other pine dominated cover types such as the wetter more productive pine class and the mixed pine-black spruce stands. The technique presented here offers a low-cost means of mapping pinelichen, an important forested cover type for populations of northern woodland caribou in BC. There also may be application to other Rangifer sub-species found in boreal and sub-boreal forests (e.g. Arseneault et al., 1997).

Mapping a large unroaded wilderness area, such as the one we studied, may appear daunting and prohibitively expensive. Our approach to mapping the $5100 \mathrm{~km}^{2}$ Wolverine study area was relatively cost effective and efficient. We employed a fixed-wing aircraft for $4.5 \mathrm{~h}$, a rotary winged aircraft for $6 \mathrm{~h}$, collection of field data entailed 15 days for two field staff, and the classification procedure for one operator 


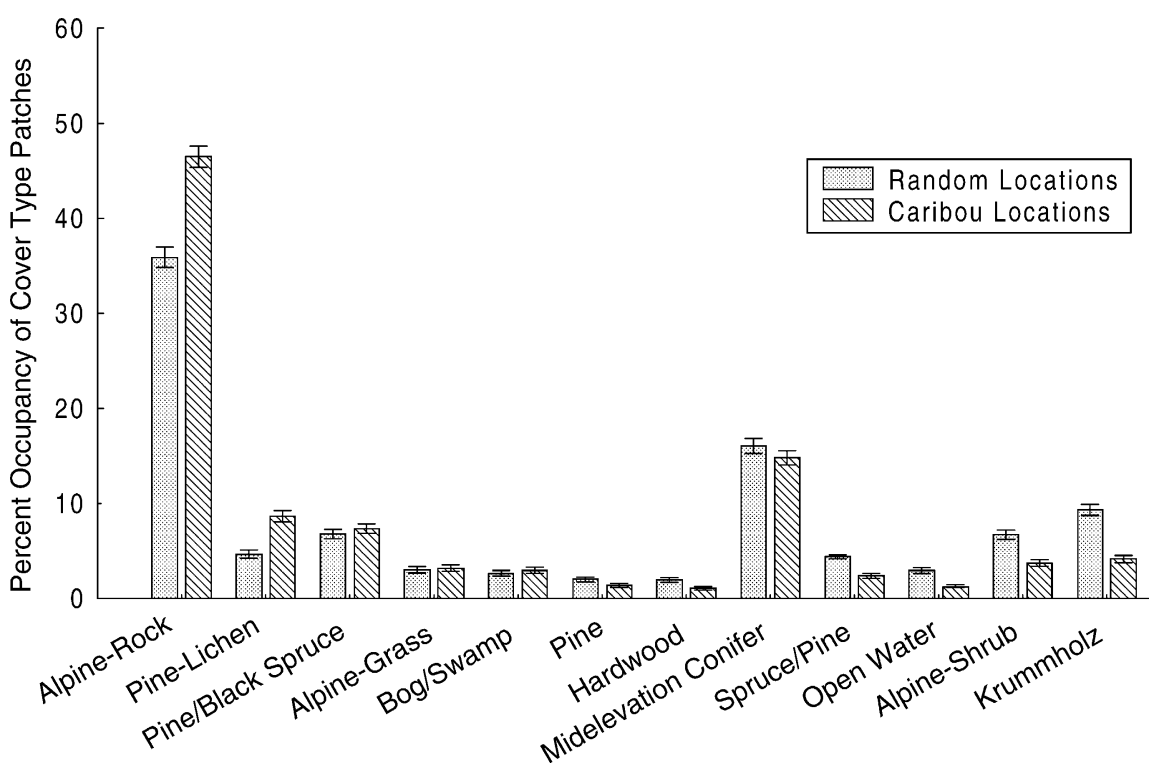

Fig. 2. Percent occurrence of aggregate cover types during small-scale movements of caribou $(n=6935)$ and corresponding random sites ( $n=6935$; error bars represent 95\% confidence intervals). Location data were collected from 1996 to 1999 during the winter (1 December to 31 March) for 16 woodland caribou of the Wolverine herd in northcentral BC, Canada (Johnson et al., 2002).

was approximately 6 weeks. By far, the most expensive component of a project such as this is the collection of ground-truth sites to train the supervised classification and the acquisition of additional samples to assess the final classified image. We did, however, achieve considerable cost savings through the use of existing-field data. We used the data and classification scheme from a previous mapping project (McKenzie, 1993), site investigation data from related research (Johnson, 2000), and publicly available data of roads/ trails, lakes, rivers, topography (government), and forest harvesting boundaries (industry). Similar ancillary data likely exists for at least portions of other project areas where existing or reliable maps are unavailable. We encourage researchers to search out and take advantage of those low-cost data sources.

Completion of this project and corresponding accuracy assessment allowed us to control the development and evaluate the vegetation maps to which we ascribed considerable importance in interpreting caribou movements and habitat affinities (Johnson, 2000). Evaluation and control were important considerations that weighed heavily in our decisions to pursue this project. Existing mapping products often claim adherence to predefined standards, but compliance is difficult to establish and violation of those standards may have implications for interpretation (Stoms, 1992; Cherrill and McClean, 1995).

\section{Conclusions}

Our results suggest that Landsat TM imagery, in combination with topographic and other ancillary data, can be used to map boreal and sub-boreal ecological types. The technique and data were successful at identifying vegetation associations important as caribou habitat. Although our method is of a lower resolution than other techniques such as TEM, it is relatively inexpensive and will meet the needs of large-scale studies of caribou-habitat relationships.

\section{Acknowledgements}

We thank S. McNay and C. Butt for providing digital files of clearcut boundaries. D. Heard, M. Gillingham, T. Bowyer, and four anonymous reviewers provided insightful comments that improved the manuscript. This work was funded by an Inventory Grant from 
Forest Renewal British Columbia, a Grant-in-Aid from the Boone and Crockett Club, a British Columbia Ministry of Environment, Lands, and Parks Environmental Scholarship, a University of Northern British Columbia Natural Resources and Environmental Studies Scholarship, and a Natural Sciences and Engineering Research Council Post Graduate Scholarship.

\section{References}

Apps, C.D., McLellan, B.N., Kinley, T.A., Flaa, J.P., 2001. Scaledependent habitat selection by mountain caribou, Columbia Mountains, British Columbia. J. Wildl. Manage. 65, 65-77.

Arseneault, D., Villeneuve, N., Boismenu, C., Leblanc, Y., Deshaye, J., 1997. Estimating lichen biomass and caribou grazing on the wintering grounds of northern Québec: an application of fire history and Landsat data. J. Appl. Ecol. 34, 65-78.

British Columbia Ministry of Crown Lands, 1990. British Columbia Specifications and Guidelines for Geomatics: Digital Baseline Mapping at 1:20,000, vol. 3. British Columbia Ministry of Crown Lands, Victoria, BC.

Cherrill, A., McClean, C., 1995. An investigation of uncertainty in field habitat mapping and the implications for detecting land cover change. Landsc. Ecol. 10, 5-19.

Congalton, R.G., 1991. A review of assessing the accuracy of classifications of remotely sensed data. Remote Sens. Environ. $37,35-46$.

Congalton, R.G., Oderwald, R.G., Mead, R.A., 1983. Assessing Landsat classification using discrete multivariate analysis statistical techniques. Photogram Eng. Remote Sens. 49, $1671-1678$.

Cumming, H.G., 1992. Woodland caribou: facts for forest managers. For. Chronol. 68, 481-491.

Edmonds, E.J., 1988. Population status, distribution, and movements of woodland caribou in west central Alberta. Can. J. Zool. 66, 817-826.

Ferguson, R.S., 1991. Detection and classification of muskox habitat on Banks Island, Northwest Territories, Canada, using Landsat Thematic Mapper data. Arctic 44, 66-74.

Franklin, S.E., Moulton, J.E., 1990. Variability and classification of Landsat Thematic Mapper spectral response in southwest Yukon. Can. J. Remote Sens. 16, 2-13.
Heard, D.C., Vagt, K.L., 1998. Caribou in British Columbia: a 1996 status report. Rangifer 10, 117-124 (special issue).

Johnson, C.J., 2000. A multi-scale behavioral approach to understanding the movements of woodland caribou. Ph.D. Dissertation. University of Northern British Columbia, Prince George, BC.

Johnson, C.J., Parker, K.L., Heard, D.C., 2001. Foraging across a variable landscape: behavioural decisions made by woodland caribou at multiple spatial scales. Oecologia 127, 590-602.

Johnson, C.J., Parker, K.L., Heard, D.C., Gillingham, M.P., 2002. A multiscale behavioural approach to understanding the movements of woodland caribou. Ecol. Appl. 12, 1840-1860.

Kardoulas, N.G., Bird, A.C., Lawan, A.I., 1996. Geometric correction of SPOT and Landsat imagery: a comparison of map- and GPS-derived control points. Photogram Eng. Remote Sens. 62, 1173-1177.

Lillesand, T.M., Kiefer, R.W., 1994. Remote Sensing and Image Interpretation. Wiley, New York.

Matthews, S.B., 1991. An assessment of bison habitat in the Mills/ Mink Lakes area, Northwest Territories, using Landsat Thematic Mapper data. Arctic 44, 75-80.

McKenzie, E., 1993. Omineca biophysical mapping project: maps and legend. Peace/Williston Fish and Wildlife Compensation Program Report No. 24, Prince George, BC.

Meidinger, D., Pojar, J., 1991. Ecosystems of British Columbia. Special Report Series No. 6, British Columbia Ministry of Forests, Victoria, BC.

Morrison, R.I.G., 1997. The use of remote sensing to evaluate shorebird habitats and populations on Prince Charles Island, Foxe Basin, Canada. Arctic 50, 55-75.

Ormsby, J.P., Lunetta, R.S., 1987. Whitetail deer food availability maps from Thematic Mapper data. Photogram Eng. Remote Sens. 53, 1081-1085.

Resources Inventory Committee, 1998. Standard for terrestrial ecosystem mapping in British Columbia. Terrestrial Ecosystems Task Force, Resources Inventory Committee, British Columbia Ministry of Environment, Lands and Parks, Victoria, BC.

Stoms, D.M., 1992. Effects of habitat map generalization in biodiversity assessment. Photogram Eng. Remote Sens. 58, 1587-1591.

Terry, E.L., Wood, M.D., 1999. Seasonal movements and habitat selection by woodland caribou in the Wolverine Herd, NorthCentral BC. Phase 2: 1994-1997. Peace/Williston Fish and Wildlife Compensation Program Report Number 204, Prince George, BC. 